\title{
Are people with normal radionuclide perfusion imaging studies better-off if they are obese?
}

\author{
Farbod Raiszadeh, MD, PhD and Mark I. Travin, MD, FASNC
}

\section{See related article, pp. 390-397}

Obesity has reached global epidemic proportions. According to World Health Organization (WHO) statistics, there are more than 1 billion overweight (body mass index, i.e., BMI, $>25 \mathrm{~kg} / \mathrm{m}^{2}$ ) adults, with at least 300 million of them clinically obese $\left(\mathrm{BMI}>30 \mathrm{~kg} / \mathrm{m}^{2}\right) .{ }^{1} \mathrm{In}$ the United States (US), there has been an alarming increase in the prevalence of obesity, with rates increasing by nearly 50\% among adults between 1980 and 2000 . The age-adjusted prevalence of obesity is about 33\%, translating into more than 70 million US adults. ${ }^{2-4}$

Obesity is a major contributor to the global burden of chronic disease, and is customarily considered to increase cardiovascular risk. While not specifically a Framingham risk factor, obesity is associated with conventional cardiac risk factors such as diabetes mellitus, hypertension, and hyperlipidemia. Nevertheless, obesity has by itself been shown to increase risk by inducing a pro-inflammatory, pro-thrombotic, and atherogenic state that leads to cardiovascular disease. ${ }^{5,6} \mathrm{On}$ a global scale, approximately $21 \%$ of ischemic heart disease is attributable to a BMI $>21 \mathrm{~kg} / \mathrm{m}^{2}$.

Obesity has been associated with increased cardiovascular morbidity and mortality separate from that related to concomitant cardiac risk factors. Obesity has detrimental effects on left ventricular (LV) morphology and microarchitecture, affecting both systolic and diastolic function, with a strong link between obesity and heart failure. ${ }^{2}$ A study with N-13 ammonia PET imaging showed that overweight and obese post-menopausal

From the Department of Nuclear Medicine and Department of Medicine/Division of Cardiology, Montefiore Medical Center and Albert Einstein College of Medicine, Bronx, NY.

Reprint requests: Mark I. Travin, MD, FASNC, Department of Nuclear Medicine and Department of Medicine/Division of Cardiology, Montefiore Medical Center and Albert Einstein College of Medicine, 111 E. 210th Street, Bronx, NY 10467-2490; mtravin@ attglobal.net. J Nucl Cardiol 2010;17:350-3.

$1071-3581 / \$ 34.00$

Copyright (C) 2010 by the American Society of Nuclear Cardiology. doi:10.1007/s12350-010-9227-1 women had reduced coronary flow reserve compared with normal weight controls. ${ }^{7}$ Increasing obesity has been correlated with earlier onset of a first non-ST-segment elevation myocardial infarction (MI), as many as 12 years earlier for patients with BMI $>40 \mathrm{~kg} / \mathrm{m}^{2} .{ }^{8}$ Obesity has been found to increase myocardial electrical instability, and is associated with a higher risk of developing atrial fibrillation, and ventricular arrhythmias that increase the risk of sudden cardiac death. ${ }^{9}, 10$ Finally, epidemiologic studies of unselected populations show that obesity correlates with increased mortality independent of cardiac risk factors. ${ }^{11-13}$ In the Framingham Heart Study, 40 year-old adults who were obese lived 6 to 7 years less than their normal-weight counterparts, similar to the risk associated with smoking. ${ }^{14}$

Nevertheless, a large number of studies have reported a surprising survival advantage associated with obesity, particularly in patients with known cardiac disease, termed the "obesity paradox." While some have conceptualized this paradox as a " $U$ " shaped curve due to underweight patients having a worsened survival, ${ }^{15}$ in fact numerous studies have consistently and definitively observed improved survival in overweight/obese vs normal weight patients. The obesity paradox has been reported in a variety of cardiovascular conditions, including hypertension, ${ }^{16}$ congestive heart failure, ${ }^{17-19}$ coronary artery disease $(\mathrm{CAD})^{20}$ including patients following $\mathrm{MI}^{21}$ or after coronary revascularization, ${ }^{22,23}$ and in patients with peripheral arterial disease. ${ }^{24}$

The obesity paradox has been observed in patients referred for various modes of non-invasive cardiac testing. In a study of $>30,000$ patients referred for echocardiography, while obese patients more often had abnormal ventricular geometry and hypertrophy, overall mortality over a mean of 3.2 years was considerably lower in obese $(3.9 \%)$ than in non-obese $(6.5 \%)$ patients. ${ }^{25}$ In a report of about 6800 veteran patients referred for exercise testing, over a mean of 7.5 years, obese patients were $22 \%$ less likely to die than those with normal weight. ${ }^{26}$

Using stress radionuclide myocardial perfusion imaging, Kang et al evaluated a group of $>4000$ patients with known CAD referred for SPECT radionuclide myocardial perfusion imaging. ${ }^{27}$ Those who were obese and overweight had, across the entire spectrum of SPECT results (normal to moderate-severely 
abnormal), a consistently lower cardiac death rate compared with normal weight patients, with BMI being an independent, inversely-related predictor of cardiac death (hazard ratio $0.95,95 \%$ confidence interval 0.92-0.98). The obesity-related survival advantage was especially so for women, patients who underwent adenosine stress, had a lower LV ejection fraction, or who showed abnormal perfusion.

Interestingly, in this study by Kang and associates, a survival advantage from obesity was not present in a larger $>10,000$ patient cohort who had suspected but no known CAD, consistent with the prior understanding that the obesity paradox occurs mostly in patients with established heart disease, but not in general populations. However, the study by Uretsky et al appearing in this issue of the Journal of Nuclear Cardiology provides not only further evidence of the obesity paradox, but now extends this finding to a group of patients without established CAD referred for SPECT imaging, and who in fact had normal images. ${ }^{28}$ In this cohort of 3673 ethnically diverse patients, those who were overweight or obese had, over an approximately $7 \frac{1}{2}$ year follow-up, a lower rate of all-cause mortality compared with normal weight patients. While patients with normal weight had a 3.2\%/ year death rate, those who were overweight (25-29.9 $\left.\mathrm{kg} / \mathrm{m}^{2}\right)$ had $1.5 \% /$ year death rate $(P<.0001)$, and those who were obese $\left(\geq 30 \mathrm{~kg} / \mathrm{m}^{2}\right)$ had an even lower $1.2 \%$ / year death rate $(P<.0001)$. After applying multivariate analysis to assess outcomes related to baseline cardiac risk factors i.e., age, gender, hypertension, smoking, hypercholesterolemia, diabetes, family history, cardiac medications, race and stress mode, having a higher weight independently decreased the risk of death with a hazards ratio of 0.54 (95\% CI $0.43-0.7)$ in overweight patients, and 0.49 (95\% CI $0.38-0.63)$ in obese patients.

Thus, as stated by the authors, "the spectrum of the obesity paradox is more extensive than previously thought.' In addition, the survival advantage of being overweight or obese included younger and older patients, men and women, patients with or without chest pain syndromes, and was especially the case for Hispanics and African Americans, in fact more so than for Caucasians, the latter finding possibly from statistical under-powering or maybe a true racial difference.

\section{WHY MIGHT THERE BE AN OBESITY PARADOX?}

A number of possible mechanisms have been offered for the "obesity paradox." There is controversy regarding whether the observed association between obesity and decreased mortality is a true, direct causal relationship, or instead a non-causal association resulting from some other confounding factor(s).
For example, some have suggested that the obesity paradox may reflect a link between smoking and lower body mass index. In patients with known CAD, lower weight may indicate a more frequent smoking history, making it appear that overweight or obese patients are better off. ${ }^{29,30}$ Nevertheless, in the aforementioned study by Uretsky and colleagues, while patients who were of normal weight more often smoked than overweight or obese patient, when multivariate analysis factored in smoking, the improved survival with obesity remained significant. $^{29}$

Another potential confounding explanation for the apparent benefit from obesity is that chronic diseases such as CHF, lung disease, kidney disease, AIDS, and progressive neurological disease, in their later stages, often result in significant weight loss. In studies demonstrating an obesity paradox, many lower-weight patients may have had an underlying serious disease, known or unknown, skewing the results. ${ }^{15}$ In addition, elderly persons tend to lose weight prior to death. ${ }^{31}$ However, such explanations would not account for findings in the study by Uretsky et al that normal weight patients, even if young, also have a higher risk of death than overweight or obese patients.

\section{POTENTIAL OBESITY EFFECT MODIFICATION FROM FITNESS}

Physical fitness appears to alter the relationship between obesity and mortality. In a study of $>12,000$ men, overweight and obese men had longer survival only if they who could achieve $>10$ metabolic equivalents during exercise testing. ${ }^{32}$ By multivariate analysis men with low fitness had the highest $(\mathrm{HR}=4.5)$ while highly fit overweight men had the lowest $(\mathrm{HR}=0.4)$ mortality risk among all subgroups. Another report of $>13000$ men with hypertension found that high-fit/ obese men had the same risk of all-cause death as their high-fit/normal weight counterparts. ${ }^{33}$ These studies suggest that fitness is a powerful effect modifier of the association between adiposity and mortality. Based on these observations, it has been proposed that overweight/obese people may be more motivated to lead a healthier lifestyle with better diet and exercise regimens, and also receive more aggressive medical cardiac risk factor treatments, while normal-weight people may be less motivated and less fit, therefore having increased risk unless they are fit as well. ${ }^{20}$

\section{PSYCHOSOCIAL RISK FACTORS AS CONFOUNDERS}

Psychosocial risk factors are known to have a role in atherosclerosis and cardiac events, and could 
potentially contribute to producing a survival advantage from obesity. ${ }^{34}$ For example depression, which can lead to weight loss, is associated with increased coronary events in both apparently healthy populations and in those with known CAD ${ }^{35}$ Other sources of stress that can lead to lower weight, such as lack of social support, work stress, marital stress, and caregiver stress, can all adversely affect cardiovascular outcomes. ${ }^{34}$ As obesity is associated with an altered stress response, the aforementioned factors could all potentially be confounders contributing to the observed obesity-cardiovascular disease relationship.

\section{POTENTIAL PROTECTIVE EFFECT OF OBESITY ITSELF}

Despite the likely effect of confounders on the observed obesity paradox, obesity itself likely has direct protective effects, particularly in people who have established cardiac disease. For example, in the setting of advanced congestive heart failure, a catabolic state with a malnutrition-inflammation complex syndrome is often present, and is detrimental. CHF patients who are obese may be protected by a greater metabolic reserve, better cytokine and neuroendocrine profiles, adipose tissue produced soluble necrosis factor alpha receptors, lower levels of circulating atrial natriuretic peptides, and attenuated sympathetic nervous system and renin-angiotensin responses. ${ }^{2,19}$

In patients with hypertension, lower systemic vascular resistance and plasma renin activity in obese compared with lean hypertensives may improve clinical outcome. ${ }^{36,37}$ In patients with CAD, obesity often leads to larger coronary arteries that may be of particular advantage in patients undergoing revascularization. ${ }^{23}$ Importantly, it has been shown that in some settings, such as in patients on hemodialysis, the protective effect of higher BMI is related to increased muscle mass, with patients having increased BMI that is mostly from adipose tissue not doing as well. ${ }^{38}$ However, in contrast, in CHF patients a higher percentage of body fat has been shown to be the strongest independent predictor of event-free survival. ${ }^{39}$ It seems, therefore, that the mechanism for the observed obesity paradox may differ depending on the underlying disease, and thus much further investigation is essential.

\section{PUBLIC HEALTH IMPLICATIONS}

The consistent finding of an obesity paradox does not at this time justify encouraging weight gain in normal weight patients or discouraging weight loss in obese patients. Adverse cardiovascular outcomes are not the only consequence of obesity as overweight patients are also at risk for numerous non-cardiac health problems. ${ }^{40}$ Until more data is available, there is no rationale for extending the obesity paradox into the realm of public health and cardiovascular prevention.

Given the increased incidence of obesity, it is important to know how to most effectively risk-stratify these patients. As noninvasive cardiac imaging, such as stress radionuclide myocardial perfusion imaging, is commonly used in these people, there is a need to investigate further how the presence of obesity interacts with image findings in terms of prognostic implications and in clinical decision making. While the current study by Uretsky et al provides an interesting perspective on this issue, it should be considered that only all cause mortality was studied, and not cardiovascular mortality nor non-lethal cardiac events. In addition, the study also does not provide data on other major cardiovascular risk factors such as specific lipid levels nor on emerging risk factors such as C-reactive protein that could provide a better understanding of the mechanism of the observed obesity paradox.

The obesity paradox is a puzzling phenomenon that contradicts the classic understanding that being overweight causes a dysmetabolic state that increases cardiovascular risk. The world's obesity epidemic mandates that it be investigated and understood more fully.

\section{References}

1. Rodgers A, Vaughan P. World Health Report 2002. Reducing risks, promoting healthy life. World Health Organization, Geneva, Switzerland, 2002. Available from http://www.who.int/whr/2002/ en/. Accessed 3/10/10.

2. Lavie CL, Milani RV, Ventura HO. Obesity and cardiovascular disease. J Am Coll Cardiol 2009;53:1925-32.

3. Flegal KM, Carroll MD, Ogden CL, Curtin LR. Prevalence and trends in obesity among US adults, 1999-2008. JAMA 2010;303: 235-41.

4. Ogden CL, Carroll MD, McDowell MA, Flegal KM. Obesity among adults in the United States-No change since 2003-2004. NCHS data brief no 1. Hyattsville, MD: National Center for Health Statistics; 2007.

5. Després J. Is visceral obesity the cause of the metabolic syndrome? Ann Med 2006;38:52-63.

6. Mathieu P, Lemieux I, Després JP. Obesity, inflammation, and cardiovascular risk. Clin Pharmacol Ther Advance online publication. 2010 Mar 3. doi:10/1038/cipt.2009.311.

7. Motivala AA, Rose PA, Kim HM, Smith YR, Bartnik C, Brook $\mathrm{RD}$, et al. Cardiovascular risk, obesity, and myocardial blood flow in postmenopausal women. J Nucl Cardiol 2008;15:510-7.

8. Madala MC, Franklin BA, Chen AY, et al. Obesity and age of first non-ST-segment elevation myocardial infarction. J Am Coll Cardiol 2008;52:979-85.

9. Wanahita N, Messerli FH, Bangalore S, et al. Atrial fibrillation and obesity-Results of a meta-analysis. Am Heart J 2008;155:310-5.

10. Messerli FH, Nunez BD, Ventura HO, Snyder DW. Overweight and sudden death: Increased ventricular ectopy in cardiomyopathy of obesity. Arch Intern Med 1987;147:1725-8. 
11. Byers T. Body-mass index and mortality (with author reply). N Engl J Med 2000;342:286-9.

12. Manson JE, Willett WC, Stampfer MJ, et al. Body weight and mortality among women. N Engl J Med 1995;333:677-85.

13. Calle EE, Thun MJ, Petrelli JM, et al. Body-mass index and mortality in a prospective cohort of U.S. adults. N Engl J Med 1999;341:1097-105.

14. Peeters A, Barendregt JJ, Willekens F, Mackenbach JP, Al Mamun A, Bonneux L, et al. Obesity in adulthood and its consequences for life expectancy: A life-table analysis. Ann Intern Med 2003;138: 24-32.

15. Ades PA, Savage PD. The obesity paradox: Perception vs knowledge. Mayo Clin Proc 2010;85:112-4.

16. Uretsky S, Messerli FH, Bangalore S, et al. Obesity paradox in patients with hypertension and coronary artery disease. Am J Med 2007;120:863-70.

17. Oreopoulos A, Padwal R, Kalantar-Zadeh K, et al. Body mass index and mortality in heart failure: A meta-analysis. Am Heart J 2008; 156:13-22.

18. Horwich TB, Fonarow GC, Hamilton MA, MacLellan WR, Woo MA, Tillisch JH. The relationship between obesity and mortality in patients with heart failure. J Am Coll Cardiol 2001;38:789-95.

19. Kalantar-Zadeh K, Block G, Horwich T, Fonarow GC. Reverse epidemiology of conventional cardiovascular risk factors in patients with chronic heart failure. J Am Coll Cardiol 2004;43: 1439-44.

20. Romero-Corral A, Montori VM, Somers VK, et al. Association of bodyweight with total mortality and with cardiovascular events in coronary artery disease: A systematic review of cohort studies. Lancet 2006;368:666-78.

21. Lopez-Jimenez F, Jacobsen SJ, Reeder GS, Weston SA, Meverden RA, Roger VL. Prevalence and secular trends of excess body weight and impact on outcomes after myocardial infarction inthe community. Chest 2004;125:1205-12.

22. Minutello RM, Chou ET, Hong MK, et al. Impact of body mass index on in-hospital outcomes following percutaneous coronary intervention (report from the New York State angioplasty registry). Am J Cardiol 2004;93:1229-32.

23. Gruberg L, Mercado N, Milo S, et al. Impact of body mass index on the outcome of patients with multivessel disease randomized to either coronary artery bypass grafting or stenting in the ARTS trial: The obesity paradox II? Am J Cardiol 2005;95:439-44.

24. Galal W, van Gestel Y, Hoeks SE, et al. The obesity paradox in patients with periopheral arterial disease: The influence of chronic obstructive pulmonary disease. Chest 2009;134:896-8.

25. Lavie CJ, Milani RV, Ventura HO, Cardenas GA, Mehra MR, Messerli FH. Disparate effects of left ventricular geometry and obesity on mortality in patients with preserved left ventricular ejection fraction. Am J Cardiol 2007;100:1460-4.
26. McAuley P, Myers J, Abella J, Froelicher V. Body mass, fitness and survival in veteran patients: Another obesity paradox? Am J Med 2007;120:518-24.

27. Kang X, Shaw LJ, Hayes SW, et al. Impact of body mass index on cardiac mortality in patients with known or suspected coronary artery disease undergoing myocardial perfusion single-photon emission computed tomography. J Am Coll Cardiol 2006;47:1418-26.

28. Uretsky S, Supraiwala A, Singh P, et al. Impact of weight on long term survival among patients without known coronary artery disease and a normal stress SPECT MPI. J Nucl Cardiol 2010;17 (in press)

29. Adams KF, Schatzkin A, Harris TB, Kipnis V, Mouw T, BallardBarbash R, et al. Overweight, obesity, and mortality in a large prospective cohort of persons 50 to 71 years old. N Engl J Med 2006;355:763-78

30. Willett WC, Hu FB, Colditz GA, Manson JE. Underweight, overweight, obesity and excess deaths. JAMA 2005;294:551-3.

31. Greenberg JA. Removing confounders form the relationship between mortality risk and systolic blood pressure at low and moderately increased systolic blood pressure. J Hypertens 2003; 21:49-56.

32. McAuley PA, Kokkinos PF, Oliveira RB, Emerson BT, Myers JN. Obesity paradox and cardiorespiratory fitness in 12,417 male veterans aged 40 to 70 years. Mayo Clin Proc 2010;85:115-21.

33. McAuley PA, Sui X, Church TS, Hardin JW, Myers JN, Blair SN. The joint effects of cardiorespiratory fitness and adiposity on mortality risk inmen with hypertension. Am J Hypertens 2009;22: 1062-9.

34. Rozanski A, Blumenthal JA, Davidson KW, Saab PG, Kubzansky L. The epidemiology, pathophysiology, and management of psychosocial risk factors in cardiac practice. The merging field of behavioral cardiology. J Am Coll Cardiol 2005;45:637-51.

35. Rozanski A, Blumenthal JA, Kaplan J. Impact of psychological factors on the pathogenesis of cardiovascular disease and implications for therapy. Circulation 1999;99:2192-217.

36. Messerli FH, Sundgaard-Riise, Reisin E, Dreslinski G, Dunn FG, Frohlich E. Disparate cardiovascular effects of obesity and arterial hypertension. Am J Med 1983;74:808-12.

37. Lavie CJ, Milani RV, Ventura HO. Obesity, heart disease, and favorable prognosis-Truth or paradox? Am J Med 2007;120: 825-6.

38. Beddhu S, Pappas LM, Ramkumar N, Samore M. Effects of body size and body composition on survival in hemodialysis patients. J Am Soc Neprol 2003;14:2366-72.

39. Lavie CJ, Osman AF, Milani RV, Mehra MR. Body composition and prognosis in chronic systolic heart failure: The obesity paradox. Am J Cardiol 2003;91:891-4.

40. Alpert JS. So, Doctor, what's so bad about being fat? Combating the obesity epidemic in the United States. Am J Med 2010;123:1-2. 